\title{
FÉLIX GUATTARI E A POLÍTICA ANTES DO SER
}

Vladimir Moreira Lima*

RESUMO: O objetivo deste texto consiste em explorar uma formulação feita por Gilles Deleuze e Félix Guattari na obra Mil Platôs, a saber, "antes do ser, há a política". Uma vez que, em outra ocasião, Deleuze fez questão de vincular esta formulação como sendo, no mínimo, um dito de Guattari, nossa proposta terá como base de investigação algumas temáticas e noções desenvolvidas na obra deste último.

PALAVRAS-CHAVE: política, práxis, ontologia.

\section{FÉLIX GUATTARI AND POLITICS BEFORE BEING}

ABSTRACT: The objective of this text is to explore a formulation made by Gilles Deleuze and Félix Guattari in their work Thousand Plateaus, namely, "before being, there is politics". Since, on another occasion, Deleuze made a point of linking this formulation as being, at least, a saying by Guattari, our proposal will have as a basis of investigation some themes and notions developed in the latter's work.

KEYWORDS: politics, praxis, ontology.

* Doutor em Filosofia pela UFRJ (PPGF-IFCS) e professor da Universidade do Estado do Rio de Janeiro (IAp-UERJ). Email: vladub77@gmail.com - Orcid: https://orcid.org/0000-0003-3189-0686 
"Eu gosto bastante da palavra ontologia. Se desconfio dela, é porque tenho a tendência a utilizá-la a torto e a direito. Há, para mim, se você quiser, focos de produção ontológica, locais de afirmação autopoiética, repetiçôes, insistências, intensidades com todo o seu cortejo de referências incorporais e de hecceidades. Tudo isso participa de uma visão um pouco animista que, verdadeiramente, não me causa problema. Onde as coisas se complicam é quando se trata de pensar uma práxis. Como, a partir dos agenciamentos de semiotização, colocar no ser novas constelações intensitárias?”.

(Félix Guattari)

\section{Introdução}

"Você pode começar a refletir, talvez, a partir de uma introdução a Hegel ou a Platão. Comece por onde quiser, o importante é saber se certas frases, certos enunciados, lhe induzem a pensar e lhe transportam, mesmo que eventualmente, para um devaneio”. É o que dizia Félix Guattari (2002, p. 26) ao ressaltar o que importa em uma experiência do pensamento que pode ser chamada de filosófica. $\mathrm{O}$ devaneio [rêverie] - e mesmo o ato de "começar a refletir" - deve ser entendido aqui como movimentos físicos, óticos, de repercussão mais ou menos rarefeita, etérea, de linhas de forças capazes de ativar transformações em um processo de produção de subjetividade. Não por acaso, na mesma entrevista, Guattari (2002, p. 21) pensava que uma das funções fundamentais da filosofia consiste em conferir à subjetividade "a densidade de um acontecimento".

Na mesma direção, a filósofa Isabelle Stengers (2018, p. 13), quando também chamava a atenção para um importante componente da prática da filosofia, afirmava: "meu métier é ler e ser transformada por isso que leio". Trata-se de uma ideia relativamente simples. E nunca é demais salientar que, certamente, não são apenas às filósofas e os filósofos que são transformados por aquilo que leem. O ponto interessante reside no fato dessa ideia indicar a persistência de um elemento e de um processo que nada têm de banal, a saber, colocar a leitura como uma dimensão importante, para aquelas e aqueles inseridos nesse território chamado filosofia, do processo vital que é ser transformado. Não a aquisição de uma competência, mas a aventura de uma experiência, nunca definitivamente conquistada, podendo sempre ser perdida e alimentando, nem mais e nem menos, um eventual aumento da potência de sentir, pensar, agir e imaginar.

O que, então, nos textos filosóficos, carregaria o embrião dessa experiência de transformação? Como também dirá Stengers (2018, p. 42), trata-se da leitura “de um belo enunciado que pode ter um ar abstrato mas, na realidade, é uma abstração viva, que desperta". A vitalidade de uma abstração possui uma diferença de natureza em relação a uma abstração morta construída a partir de um isolamento e de um aplainamento das texturas daquilo que poderia entrar em possíveis conexões. Uma abstração vital consiste precisamente na instauração de um espaço-tempo em que ela se movimentará na medida em que efetua a extração de possíveis - tornando-os “ao alcance das mãos”, pensáveis e experimentáveis - de conexões virtuais. O que ela desperta está adormecido e, ao mesmo tempo, é inteiramente criado pela 
própria abstração (sendo inimaginável sem ela). Toda abstração produz, segundo a cintilante expressão de Guattari (1992, p. 36), uma espécie de “catálise poético-existencial”"1. O mundo se enriquece, um pouco que seja.

A obra de Gilles Deleuze e Félix Guattari, considerando o que eles escreveram conjuntamente ou não, está repleta desse tipo muito especial de abstração e assim permanecerá - ainda que sempre coexistindo com a tentativa de domesticação constante que este pensamento sofre quando reduzido a um modelo teórico, destinado a funcionar como um aglomerado de palavras de ordem ou, pior, como fundador de novos tribunais filosóficos, morais e políticos.

Dentre tantas abstrações vivas, pensamos haver um enunciado muito especial na obra de Deleuze e Guattari. Ainda que tenha sido explicitado, dito com todas as letras, em Mil Platôs, segundo tomo de Capitalismo e esquizofrenia, ele possui uma irradiação muito vasta que afeta toda a obra da dupla. Tal enunciado, que esse texto se esforçará por tratar, não fornece nenhuma síntese, não é mais verdadeiro, fundamental e, por isso, não detém o privilégio da experiência de ativações de transformações possíveis a partir da obra de Deleuze e Guattari. Evidentemente, isso não pode ser universalmente e quantitativamente medido, quanto mais determinado a priori. Sobre o enunciado que aqui estamos nos referindo, a única afirmação digna de ser feita é: trata-se de uma abstração viva. Portanto, sua potência, a ser continuamente avaliada, diz respeito apenas e exclusivamente às conexões transversais que sem ele não poderiam ser pensada. "Transversalidade jamais dada como 'já-aî', mas sempre a ser conquistada através de uma pragmática da existência”, tal como escrevia Guattari (1992, p. 173).

O enunciado em questão aparece no platô 8, intitulado "1874 - Três novelas ou 'o que se passou?", onde podemos ler a seguinte formulação: "Pois, antes do ser, há a política” (DELEUZE e GUATTARI, 1996, p. 78).

\section{Ressonâncias}

Se considerarmos todas as obras de Deleuze e Guattari (mesmo entrevistas, artigos, etc.), existe apenas mais uma outra ocorrência ipsis litteris dessa formulação. Em Diálogos, publicado três anos antes de Mil Platôs, Deleuze (2004, p. 28) afirmava: “Como diz Félix, antes do Ser há a política”. Além, nesse caso, da insignificante letra maiúscula para escrever a palavra "Ser", trata-se de uma prática não muito comum em que um dos dois faz questão de vincular uma noção, um conceito, uma formulação, ao outro. E não podemos deixar de mencionar a expressiva quantidade de contrassensos existente sobre o encontro, o acontecimento, Deleuze-Guattari. Como dizia o próprio Deleuze (1992, p. 35), “por trás dos

\footnotetext{
${ }^{1}$ Philippe Pignarre e Isabelle Stengers (2005, p. 167) - pensando, ao que tudo indica, na ideia de catálise tal como aparece na sua relação direta com o possível e com o a criação no último parágrafo de As três ecologias de Guattari - escreviam o seguinte: "Félix Guattari evocava a respeito disso um processo de 'catálise existencial', cada 'criação', ou reconquista, podendo suscitar repercussões sobre o modo do 'se é possível', podendo despertar o apetite que fará existir um outro possível, em outro lugar”.
} 
contrassensos sempre há uma política”. E, aqui, há tanto uma política do pensamento quanto um modo de pensar a política que está em jogo².

Por exemplo, nos restringindo apenas ao campo do "fogo amigo", um dos mais extravagantes contrassensos, pelo menos dentre aqueles que estão publicados, talvez seja a posição de François Dosse (2010, p. 22) quando afirma categoricamente que Deleuze escreveu sozinho a obra O que é a filosofia? e apenas concedeu colocar o nome de Guattari como autor a pedido de terceiros, com o intuito de animar o amigo em comum que estava deprimido.

Do mesmo modo, ainda que com o objetivo oposto ao de Dosse, podemos mencionar o sentimento geral que acompanha às opiniões de Stéphane Nadaud (GUATTARI, 2012 e 2013, p. 13), apresentando um Guattari mesquinho, ciumento, contribuindo como pode, totalmente a reboque de Deleuze.

Na direção inversa, vale lembrar o que diz Antonio Negri (1994) em uma entrevista, comparando Deleuze e Guattari em relação ao - falso - problema de quem teria ultrapassado, superado, radicalmente o estruturalismo. Algo apenas plenamente realizado, para Negri, por Guattari. Na medida em que a obra deste último vem sendo gradualmente analisada, outros impertinentes elementos são acrescentados na defesa de uma suposta superioridade de Guattari sobre Deleuze: militante, profissional do domínio psi, homem das práticas, pensando problemas reais, históricos, institucionais e não questões metafísicas...

O único motivo para chamar atenção para estes contrassensos se dá pela escolha do caminho aqui tomado e, por isso, um risco que o espreita: pensar o enunciado "antes do ser, há política” considerando, interessadamente, uma certa singularidade que o acompanha ao ser vinculado, como Deleuze fez questão de atrelar, ao nome de Guattari. Porém, trata-se apenas de uma recriação de uma singularidade a luz de uma recursividade própria de algo que é primeiro e determinante: o agenciamento coletivo de enunciação que atravessa o encontro Deleuze-Guattari e do qual o enunciado "antes do ser, há a política” é fruto.

Se há algo de interessante nesses contrassensos é o fato de se basearem sempre em uma espécie de infâmia. Pois, como pensava o escritor Albert Cossery (2004), a infâmia ocorre quando a questão do valor passa ao primeiro plano por meio de uma situação vergonhosa, tornando possíveis dignos aprendizados. No cerne destes contrassensos está uma questão de percepção acerca daquilo que pode uma conexão em heterogêneses. Por isso não se trata, aliás, de um problema puramente "metodológico" e exterior ao enunciado que aqui queremos pensar. Antes do ser, há uma política do agenciamento, do esmagamento ou do cultivo da experiência de uma conexão no sentido forte, isto é, um processo de heterogêneses.

\footnotetext{
${ }^{2}$ Não por acidente, é em relação a esta questão que o tal enunciado aparece em Diálogos: "Éramos só dois, mas o que para nós contava era menos trabalhar juntos do que esse fato estranho de trabalhar entre os dois. Cessávamos de ser 'autores'. E este entre-os-dois reenviava para outras pessoas, diferentes para um e para o outro. O deserto crescia, mas povoando-se à medida que crescia. Isto não tinha nada a ver com uma escola, com processos de recognição, mas muito com encontros. E todas essas histórias de devires, de núpcias contra-natura, de evolução a-paralela, de bilinguismo e de roubo de pensamentos, foi o que eu tive com Félix [...] Nestas condições, a partir do momento em que existe esse tipo de multiplicidade, trata-se de política, de micropolítica. Como diz Félix, antes do Ser há a política” (DELEUZE, 2004, p. 28).
} 
Nunca se sabe o que se pode, e mesmo o que se é, sobretudo o que se expressa, fora dos agenciamentos. Não existem, tal como esse conceito é pensado por Deleuze e Guattari (cf. por exemplo 1988, 1996 e 1989) inúmeras vezes, entidades que passam de um agenciamento ao outro permanecendo as mesmas. Um agenciamento não é nunca um simples contexto. O que se é e, acima de tudo, o que pode, um corpo, uma noção, um grupo, é descoberto, experimentado e forjado através das conexões de que se é capaz, das relações de dependência, dos vínculos e encontros que são nutridos em uma dada situação, em um dado meio. Vale retomar, a este respeito, a seriedade do humor de Deleuze em uma das apresentações do modo como trabalhavam juntos. Deleuze está explicando o procedimento que Guattari chamava de "afinação".

Um se cala quando o outro fala. Não é apenas uma lei para que nos compreendamos, para que nos ouçamos, mas significa que um se põe perpetuamente a serviço do outro. Aquele que se cala está por natureza a serviço daquele que fala. Trata-se de um sistema de ajuda mútua onde aquele que fala tem razão pelo próprio fato de estar falando. A questão não é 'discutir'. Se Félix me disse alguma coisa, eu só tenho uma função: busco o que pode confirmar uma ideia tão bizarra ou louca (e não 'discutível'). Se eu lhe dissesse: 'no centro da terra tem geleia de groselha', seu papel seria buscar o que poderia dar razão a uma ideia como essa (se é que isso é mesmo uma ideia!). É o contrário, pois, de uma sucessão ou troca de opiniões. A questão não é saber se a opinião é minha ou dele e, aliás, uma objeção nunca será feita. Só haverá melhora (DELEUZE e GUATTARI, 2015, p. 167).

Dar força para um devaneio, para uma divagação, através de enunciados e noções funcionando como abstrações vivas, não poderia ser um dos modos de pensar a própria consistência da conexão Deleuze-Guattari de ativar e materializar transformações mútuas? Portanto, não é o nome de Guattari, e sua obra solo, que poderiam aparecer como a fonte de inteligibilidade do enunciado "antes do ser, há a política" mas, ao contrário, é este enunciado que pode funcionar como uma chave analítica e transversal para percorrer as multivalências das forças, das noções, das questões e conexões que compõe o pensamento de Guattari. E que, talvez, mereçam ser recompostas, prolongadas, recriadas. Para ecoar a perspectiva rizomática que é apresentada como platô-introdução de Mil Platôs, é o caso de dizer que a escolha de uma entrada (em uma obra, em um problema, em uma situação) pode ser avaliada segundo a capacidade que ela carrega para fazer proliferar as saídas.

Como já foi dito, apesar da afirmação de Deleuze, não encontramos em nenhuma parte da obra de Guattari uma formulação idêntica ao enunciado a ele atribuído. Isto não significa que algumas outras formulações não ressoem - e vice-versa - com o mesmo. Acrescentamos, aliás, que a utilização da palavra ressonância, aqui, tem um sentido preciso. Trata-se tanto de prescindir do entendimento que tomariam esses enunciados que ressoam como equivalentes, quanto impedir de entrar no jogo comparativo de semelhanças e diferenças que eles podem apresentar (o que supõe a equivalência de fundo). A ressonância, entre eles, que ocorre em muitas direções e sentidos, deve designar, fundamentalmente, a existência de um campo problemático, ele mesmo singularizado, no qual esses enunciados se encontram, 
isto é, se situam uns em relação aos outros na medida em que são irrigados por um problema específico. Problema este que poderia ser esboçado sucintamente mais ou menos assim: como funciona um ato de criação política?

Para indicar de maneira breve, toda esta temática já está inteiramente presente no primeiro livro de Guattari, Psicanálise e transversalidade: ensaios de análise institucional, composto na sua maior parte por textos dos anos 60. Quando Guattari se esforça em elaborar a ideia de transversalidade, é a política antes do ser que já está sendo trabalhada. Exatamente pelo fato da transversalidade ser uma noção e um processo do pensamento destinado a sustentar, a negociar, a trabalhar, a ideia de práxis de conexões institucionais que prescindiriam de toda forma de homogeneização. Mais precisamente, Guattari se concentrava em pensar a natureza do desejo e da vida que uma instituição é capaz a partir das conexões que ela poderia colocar para funcionar a despeito mesmo de suas estratificações mais ou menos ordinárias. Como a vida coletiva, dentre outros impasses, submetida a existir em um lugar altamente estratificado, cujas reificações de papéis, funções e valores não param de atuar, poderia se enriquecer continuamente? É o problema daquilo que Guattari batizava de grupo-sujeito, manifestando uma tendência de criação institucional.

A transversalidade é uma dimensão que pretende superar os dois impasses, quais sejam o de uma verticalidade pura e o de uma simples horizontalidade; a transversalidade tende a se realizar quando ocorre uma comunicação máxima entre os diferentes níveis e, sobretudo, nos diferentes sentidos. Isso constitui o próprio objeto de pesquisa do grupo-sujeito. Nossa hipótese é a seguinte: é possível modificar diferentes 'coeficientes de transversalidade' inconsciente nos diferentes níveis de uma instituição (GUATTARI, 2004, p. 111).

Trata-se de uma importante peça que está se instalando: a criação de vias ou componentes de passagem; a criação de práticas que podem cultivar, sob um certo aspecto, de um certo modo, conexões que, mais tarde, serão chamadas de heterogenéticas. Aí se apresenta um elemento singular do ato de criação política e, ao mesmo tempo, a disposição própria da criação política para habitar transversalmente - outras práticas de criação.

É neste contexto que surge a análise institucional. Uma vez instalada, esta perspectiva sofrerá e desencadeará muitas ressingularizações (e retomadas) na medida em que dobra e se desdobra no encontro com outras noções, problemáticas, situações históricas e concretas vividas por Guattari, inclusive àquelas oriundas dos coletivos e organizações militantes pelos quais passa. Para citar alguns exemplos, nos anos 70, todas as inflexões em torno da noção de máquina, como é o caso de $O$ anti-Édipo, escrito com Deleuze, a proposição de uma revolução molecular que encontramos em La révolution moléculaire e, ainda, a ideia de uma micropolítica ${ }^{3}$, disseminada de modo explícito nesta última obra, em Kafka: por uma literatura menor,

\footnotetext{
${ }^{3}$ A micropolítica, assim, ao contrário do que rapidamente somos tentados a pensar, inclusive por conta de riscos imanentes à apresentação da própria noção de micropolítica, não é simplesmente uma política do molecular em oposição a uma política do molar que deveria, por sua vez, ser designada pelo termo macropolítica. Ela é uma noção de política destinada a pensar os atravessamentos contínuos e o emaranhado irredutível entre as linhas molar, molecular e de fuga (cf., por exemplo, 1988 e 1996). Na verdade, se há uma afinidade da micropolítica com alguma dessas linhas, ela se dá com a linha de fuga. Mas não
} 
também assinado com Deleuze, ou ainda em $O$ inconsciente maquínico: ensaios de esquiroanálise, dão testemunho de algumas dessas ressingularizações.

Vale mencionar, assim, uma passagem presente em La révolution moléculaire que ressoa diretamente o enunciado "antes do ser, há a política". Guattari (2012, p. 511) escreve: "Existem tantos modos de existência quanto modos de agenciamentos". E complementa:

Nessa condições, não haveria espaço para considerar "graus" de existência, "graus de verdade". Tudo existe e tudo é verdadeiro (...) O corpo sem órgãos da existência, a existência do objeto puro além do ser e do não ser, não é uma categoria universal indiferenciada. É o lugar de todas as diferenciações maquínicas abstratas fora das coordenadas (plano de consistência).

Em O inconsciente maquínico, outra ressonância que reverbera esta última: “ser-em-si ou ser-para-si só valem relativamente para ser-para-a práxis, ser-para-o agenciamento" (GUATTARI, 1988, p. 156). Salientamos apenas, dessas passagens, algo ao qual retornaremos: a valorização em pensar a política sem recorrer a uma divisão, ela mesma já política, do que é real e do que não é - divisão sempre acompanhada do corte entre aqueles e aquelas que acreditam, se iludem e devem ser governados por aqueles que possuem o poder para determinar a realidade, a verdade e o valor de uma prática ${ }^{4}$. Sem nos encaminharmos rápido demais para o que à primeira vista poderia ser qualificado como o lado inverso, a saber, aquele de uma política como ordem estritamente convencional e humana, uma vez que permanecemos com os mesmos pressupostos que fundamentam às ações em supostos parâmetros universais de realidade, a questão que se põe se traduz no seguinte movimento: pensar a política antes do ser também implica pensar uma política radicalmente construtivista, um construtivismo profundamente não-relativista.

Nos anos 80, por sua vez, a densa elaboração em Cartographies schizoanalytiques e em As três ecologias, com o tema da metamodelização esquizoanalítica ${ }^{5}$ e da ecosofia, também não escapam desse vasto campo

pelo fato desta implicar uma região do real mais fundamental que as supostas regiões que seriam representadas pelo molar e o molecular, e sim pelo fato da linha de fuga dramatizar, de modo mais intenso, sempre pragmática e farmacologicamente, a potência da criação e da resistência de modo inseparável das dosagens que podem instaurar uma brutal paixão de autodestruição de si, dos outros e, claro, da própria práxis de criação e resistência em questão. Em certo sentido, pode-se dizer, o que não deixa de afetar a compreensão da política antes do ser, que a noção de micropolítica é uma noção de política que surge após a política, em seu sentido habitual, ser posta à prova das linhas de fuga (sempre considerada na imanência mútua das linhas) e de seu desafio existencial incontornável, isto é, jamais resolvido de uma vez por todas.

${ }^{4}$ Um outro efeito possível do enunciado "antes do ser, há a política” nos conduz a pensar, talvez, que Guattari esteja querendo neutralizar, o que já constitui um ato de luta política, algo que poderia ser chamado de "vanguarda molecular", ou seja, modos mais ou menos imperceptíveis de certos grupos e indivíduos, nos domínios mais diversos, pretenderem, com níveis distintos de arrogância, representar, ensinar, comandar, guiar e domesticar processos singulares de criação. A vanguarda molecular investe mas não se resume, assim, às formas reconhecidas das vanguardas políticas. De algum modo, é esse o ponto de Guattari, por exemplo, em Psicanálise e transversalidade (2004, pp. 359-366) e em La révolution moléculaire (2012, por exemplo, mas não só, pp. 27, 76-79).

${ }_{5}^{5}$ Como uma variação e uma espécie de relançamento da análise institucional pensada por Guattari nos anos 60 e considerada como algo relativamente domesticada (cf. GUATTARI, 2005, p. 275), a esquizoanálise não parou de ser trabalhada durante toda a obra de Guattari. Não podemos deixar de apontar, portanto, que o enunciado que aqui estamos trabalhando surge, em Mil Platôs, quando Deleuze e Guattari (1996, p. 77-78) estão pensando justamente a natureza dessa práxis: "A esquizoanálise não incide em elementos nem em conjuntos, nem em sujeitos, relacionamentos e estruturas. Ela só incide em lineamentos, que atravessam tantos os grupos quanto os indivíduos. Análise do desejo, a esquizoanálise é imediatamente prática, 
de ressonância. Em uma longa passagem, desse momento, Guattari explicita outro componente importante do problema: a anterioridade, o primado, o privilégio da política em relação ao ser não implica um abandono da própria noção de ser e nem mesmo da perspectiva ontológica.

Uma tal associação entre o conceito de existência e aquele de uma consistência, portadora de heterogeneidade e de precariedade, implica uma renúncia às oposições massivas binárias do tipo: essência/ existência, Ser/Nada, etc. [...] Assim, substituímos o corte brutal Ser/Nada pela gama aberta de intensidades existenciais [...] O ser é modulação de consistência, ritmo de montagem e de desmontagem. Sua coesão, senão sua coerência, não revela nem um princípio interno de eternidade nem um enquadramento causalista extrínseco que tomaria em conjunto os existentes num mesmo mundo, mas revela a conjugação de processualidade de consistência intrínseca engajando elas mesmas relações generalizadas de transversalidade existencial (GUATTARI, 1989, p. 138).

Há uma política antes do ser e há uma ética que acompanha a modulação das consistências do ser. Nesses anos 80 e, sobretudo, no início dos anos 90, a temática da ecosofia e da caosmose demandou continuamente a Guattari pensar uma forma muito especial de responsabilidade, propriamente ética, que coexiste com o ato de criação política e, ela mesma, também é inseparável do processo de criação. Não se trata, nisso que denomina ética, apenas a prática de cuidado e atenção ontológica aos atos de criação propriamente políticos e existenciais. Também a ética é uma práxis de criação. Especificamente, de criação da responsabilidade, das maneiras de responder ao que exige um ato de criação existencial em vias de ser instaurado. Guattari chamou, nada mais e nada menos, de "responsabilidade ontológica" uma "processualidade criativa [...] que liga a liberdade e sua vertigem ética no coração das necessidades ecossistêmicas".

Há uma certa liberdade, um campo de matérias de opções (1988), de escolhas, que precedem o ser, que participam de sua composição. E, mais uma vez, isso não deve ser entendido como um humanismo supremo, que transforma o sujeito, depositário habitual da liberdade e da escolha (do livrearbítrio), em uma espécie de Deus ou Natureza, capaz de ser causa do ser. Em Chaosmose, quando trabalhava ainda outra ressingularização, aquilo que chamava de paradigma estético, Guattari escrevia:

o novo paradigma estético tem implicações ético-políticas porque falar em criação é falar de responsabilidade da instância criada diante da coisa criada, inflexão de estado de coisa, bifurcação além de esquemas preestabelecidos, aquisição, aí ainda, de uma espécie de alteridade em suas modalidades extremas. Mas a escolha ética não emana mais de uma enunciação transcendente, de um código de lei ou de um deus único e todo-poderoso. A gênese da enunciação é ela mesma tomada no movimento de criação processual.

imediatamente política, quer se trate de um indivíduo, de um grupo ou de uma sociedade. Pois, antes do ser, há a política. A prática não vem após a instalação dos termos e de suas relações, mas participa ativamente do traçado das linhas, enfrenta os mesmos perigos e as mesmas variações quando que elas". Sobre as relações entre esquizoanálise e a própria ideia de micropolítica, cf. LIMA, 2019. 
Chaosmose possui um lugar a parte nos enunciados que estão em um campo de ressonância com a formulação "antes do ser, há a política”. Quando Guattari requalificava precisamente sua perspectiva maquínica a partir do que denominava "Universo de valor" e quando pensava a vinculação da ética com uma responsabilidade ou pragmática ontológica, também dizia com todas as letras: "o maquinismo, no sentido em que eu entendo, implica um duplo processo autopoiético-criativo e ético-ontológico (a existência de uma 'matéria de escolha') completamente estrangeira ao mecanismo". E é exatamente aqui, na passagem onde surgem estas elaborações que, provavelmente, encontramos a formulação mais próxima do enunciado “antes do ser, há a política”. Guattari (1992, p. 150-151) escreverá: “o ser não precede a essência maquínica; o processo precede a heterogênese do ser".

Formulação que é reverberada por outra presente em uma entrevista do mesmo ano. Quando questionado sobre um certo "pragmatismo" que haveria em suas análises ${ }^{6}$, Guattari (2013, p. 348-349) assentia e acrescentava: “a práxis precede o ser”. Tal formulação, aliás, era dita sem antes não deixar de alertar que é "a categoria mesma de ser que está em perigo. A filosofia sempre viveu em uma espécie de passividade em relação ao ser. Hoje, nós produzimos uma homogênese do ser”.

Trata-se, em suma, do confronto de uma política da existência que instaura uma heterogênese do ser e que, por isso, busca conjurar uma política da existência que se estratifica em um ser homogenético. Este que, por sua vez, estabelece a redundância entre os dispositivos de equivalências generalizadas capitalísticas que agem nos mais diversos domínios - formalmente capitalistas ou não. Em Chaosmose, esta questão é assim colocada:

A lógica dos conjuntos discursivos busca uma espécie de acoplamento desesperado no Capital, no Significante, no Ser com um S maiúsculo. O Capital é o referente da equivalência generalizada do trabalho e dos bens; o Significante, o referente capitalístico das expressões semiológicas, o grande redutor da polivocidade ontológica [...] São referentes vazios, que fazem o vazio, que instauram a transcendência nas relações de representação. A escolha do Capital, do Significante e do Ser participam de uma mesma opção ético-política. O Capital esmaga todos os outros modos de valorização. O significante abafa as infinitas virtualidades das línguas menores e das expressões parciais. O Ser funciona como um aprisionamento que nos torna cego à riqueza e a multivalência dos Universos de valor que, no entanto, proliferam sob nossos olhos. Existe uma escolha ética em favor da riqueza do possível, uma ética e uma política do virtual que descorporifica, desterritorializa a contingência, a causalidade linear, os pesos dos estados de coisas e das significações que nos assediam (GUATTARI, 1992, p. 48-49).

Assim sendo, sem deixar para trás o percurso feito, como em um devaneio, e se um outro turbilhão de associações chegasse e forçasse com que nos movimentássemos por outros caminhos?

\footnotetext{
${ }^{6}$ Sobre a existência de uma "práxis pragmática" no pensamento de Guattari e a importância central da noção de práxis em sua obra, cf. LIMA, 2019.
} 


\section{Recriação da política}

"Antes do ser, há a política". Enunciado curto que contém duas palavrinhas - ser e política - cuja equivocidade, definições, significados e sentidos se estendem ao infinito. Mais importante: se pensamos o acontecimento contingente da invenção da política no meio grego que estabelece a democracia bem como a filosofia que aí estava sendo feita, não por coincidência àquela majoritariamente considerada como "clássica", como o "período de ouro", onde está justamente Platão, não há uma determinação sequer do ser que não seja também uma determinação do que é a política (e vice-versa).

A imagem do ser aí vencedora, o paradigma de um real mais substancial, essencial, que toda realidade posta como acidental, ao mesmo tempo unificando, permitindo e explicando a diversidade do que existe, constitui-se na edificação de um princípio nunca dado na existência e, portanto, capaz de julgála de modo transcendente, impedindo que a questão de uma criação ontológica sui generis pudesse ser posta. Tal imagem do ser é composta pelo mesmo movimento - tendo em vista a sua expressão genética inseparável da invenção da democracia - que compõe e ocupa o coração da política. Um princípio igualmente unificador dos homens, um fundamento, um solo comum, pretendendo ser capaz de reger suas relações, de permitir suas particularidades e liberdades, cuja cristalização é instituída na forma da lei. O ser promove um comum entre os seres, os existentes, incluído aí o homem. Plano esse mais ou menos hierarquizável conforme o gosto do filósofo. A política, através da lei, por sua vez, pretende promover a comunidade entre os homens (e homens bem seletos) e cuja marca é a soberania humana diante de outros modos de existência.

Seria interessante reter dessa sintonia entre filosofia e política (ser e lei) alguns pontos. Primeiramente, que ambas procedem através de uma abstração morta, isto é, a partir da tentativa de extrair o homem e a realidade de seus meios, de seus vínculos, de seus pertencimentos. A própria e abrupta separação entre o homem e a realidade, a cultura e a natureza, modernamente, o sujeito e o objeto, é já fruto da abstração entre o espírito e a matéria que foi reproduzida à exaustão pela tradição filosófica - aquilo que Guattari, retomando a expressão de Pierre Levy, chamava de "cortina de ferro ontológica".

Arrastados e frutos desta abstração, um sujeito ou um objeto qualquer, valem o que valem, podem o que podem, são o que são, na medida em que estão em conformidade com um determinado comumabstrato. Acerca da invenção da política, François Châtelet (1973, p. 19) escrevia algo muito interessante a este respeito, quando pensava a "ordem da cidadania, na qual o destino de cada um é definido não pela proximidade aos deuses, nem por pertencer a uma família, nem pela obrigação de lealdade a um chefe, mas pela relação ao princípio abstrato que é a lei”. Tal é a marca da desterritorialização negativa, para falar como Guattari (2012, p. 513-514), constitutiva dos estratos da realidade política e da política como única realidade, da política da homogênese da realidade. Não seria esse o mesmo movimento que contribuiu decididamente para fundar uma imagem do ser como instância que não pode ser trabalhada, 
enriquecida, longe de toda práxis? Não se trata aí de um procedimento análogo que imputa ao ser um princípio de constância e homogeneidade? A ordem da política não parece ganhar toda autonomia, uma suposta liberdade, na mesma medida em que, inversamente, a realidade se enrijece em leis da natureza inscritas em um suposto destino determinista?

Em segundo lugar, a política e o que mais tarde se chamará de ontologia não deixam de ser os signos da maneira grega, ocidental, de colocar um problema interessante que, talvez, exista à sua revelia: como pensar, como sentir e como agir diante do encontro, da conexão, da coexistência, entre heterogêneos? Inclusive quando se trata de negar o direito à existência de algum modo de existência heterogêneo, é também disso que se trata. Não há distribuição da heterogeneidade, fundada em um ser comum-abstrato que não acaba por decidir quais seres são dignos de existir como diferentes em relação ao princípio unificador e, consequentemente, aqueles que entrarão na região do não-ser, ou seja, aquela heterogeneidade que não aparece sequer como tal, tendo seu próprio “direito à existência” negado. É isto que está em jogo naquilo que Deleuze e Guattari, também em Mil Platôs, chamaram de racismo europeu, que procede por captação das zonas de dessemelhança, onde sequer existe heterogeneidade, mas apenas aqueles ou aquilo cujo crime é não se assemelharem aos que estão em conformidade com o princípio comum-abstrato e com a ordem erigida por aqueles que fundam tal princípio. Como escreviam Deleuze e Guattari (1996, pp. 45-46):

O racismo europeu como pretensão do homem branco nunca procedeu por exclusão nem atribuição de alguém designado como Outro: seria antes nas sociedades primitivas que se apreenderia o estrangeiro como um "outro". O racismo procede por determinação das variações de desvianças, em função do rosto Homem branco que pretende integrar em ondas cada vez mais excêntricas e retardadas os traços que não são conformes, ora para tolerá-los em determinado lugar e em determinadas condições, em certo gueto, ora para apagá-lo no mudo que jamais suporta a alteridade (é um judeu, é um árabe, é um negro, é um louco... etc,). Do ponto de vista do racismo, não existe exterior, não existem as pessoas de fora. Só existem pessoas que deveriam ser como nós, e cujo crime é não o serem [...] O racismo jamais detecta as partículas do outro, ele propaga as ondas do mesmo até à extinção daquilo que não se deixa identificar (ou que só se deixa identificar a partir de tal ou qual desvio).

E, em terceiro lugar, o que talvez constitua o que há de decisivo nisso que podemos chamar de tradição ocidental (a maneira pela qual ela se forjou ao se identificar com certos valores, práticas, instituições e reproduzir sua própria história supostamente originária), herdeira tanto da política quanto da filosofia grega vencedora, é justamente o fato de, com uma mão, colocar o problema da conexão entre heterogêneos de um tal modo em que ele é sempre respondido pela necessidade da presença desse comum-abstrato reger a conexão e, por sua vez, limitar ou mesmo conjurar totalmente o grau de intensidade do que podem as conexões entre heterogêneos. Em outras palavras, não há conexão entre heterogêneos que não seja realizada através de uma forma de equivalência generalizada: ser e lei - o ser sempre tendo a força de uma lei e a lei de impor ou, no mínimo, de carregar o ser e seus estratos de 
realidade. E essa mesma tradição, com a outra mão, o que não quer dizer depois, outorgar-se o direito de definir o conteúdo do ser, o conteúdo da lei, bem como delimitar às fronteiras daqueles que podem definir esses conteúdos e aqueles que não estão autorizados.

Deleuze e Guattari também são herdeiros dessa tradição. Trata-se, no entanto, nesse caso, como também escreveu Stengers, em "se ressituar como herdeiro de um desastre e não apenas de um progresso, [pois isso] permite criar graus de liberdade um pouco inesperados” (2018, p. 25). Eles não pretendem aperfeiçoar esse problema, melhorar a resposta. Nem fingir que poderiam fazer uma inocente tabula rasa do mesmo (e pretender começar do zero). "Antes do ser, há a política” implica, sem dúvida, que se permanece pensando em termos políticos e ontológicos ou, mais precisamente, diante das consequências de uma história, a da filosofia e, talvez, a do ocidente, que se desdobrou a partir de uma tradição que pensa em termos políticos e ontológicos sobretudo quando não se fala de política e de ontologia.

Observamos, aqui, que estamos entendendo ontologia em um sentido largo, onde as supostas viradas epistemológicas, antimetafísicas, linguísticas, cognitivistas e mesmo as reviradas ontológicas da filosofia contemporânea, por exemplo, se desenrolaram participando do mesmo movimento epistemologicamente crítico, politicamente conquistador, instaurado pelo discurso do ser: a pretensão de definir, universalmente e de uma vez por todas, antes do encontro e da conexão entre heterogêneos, para tratá-los, as supostas bases que legislariam sobre os possíveis de todo tipo de relação, conferindo ou não valor ao permitir o atributo de realidade. Platão, Descartes, Kant e Heidegger, sob esse prisma, não se distinguem tanto assim. E mesmo Spinoza, Nietzsche, Deleuze ou quem quer que seja podem, ocasionalmente, fazer parte dessa história, caso suas filosofias, independentemente do esforço que fizeram, funcionem como modelizações teóricas homogeneizantes das singularidades e dos processos de heterogêneses. Não há um pensamento da política que não esteja às voltas com uma política do pensamento, da criação e da potência em captar a criação segundo seus meios singulares de funcionamento, expressão e existência.

Como, então, resistir a essa herança e a esse problema sobretudo quando não se escolhe recebêlos? O que não quer dizer, em hipótese alguma, que se receba como uma fatalidade determinista. Ou ainda: como não viver de seu patrimônio, de sua eterna aplicação, esperando os rendimentos futuros, mesmo e sobretudo quando se acredita estar fora dela? Em termos deleuze-guattarrianos, a questão também poderia assim ser apresentada: como pensar a partir das linhas de fuga que, por sua vez, insistiram em ser cultivadas no interior mesmo dessa tradição? Como captá-las e, ao mesmo tempo, criá-las ou recriá-las, já especulando que elas existem?

Creio que a aposta de Deleuze e Guattari passe por aquilo que Ovídio Abreu (2003) pensou como sendo um verdadeiro procedimento, de subtração, presente na obra de Deleuze. No caso aqui em jogo, gostaríamos de sublinhar a subtração da resposta que postula uma abstração morta, uma equivalência, como solução para o problema da conexão entre heterogêneos. Porém, como foi dito, essa resposta não é uma possibilidade para este problema, ela faz parte de sua expressão, de sua mais íntima constituição. 
Desse modo, a subtração dessa resposta implica uma recomposição do problema. E essa recomposição ou recriação implicará, por sua vez, uma intensificação do caráter radicalmente singular do encontro e da conexão entre heterogêneos. De um tal modo que, em nenhum momento, para pensá-los, para criar conexões, se abra mão das heterogeneidades que lhes constituem. O que nos encaminha diretamente até o ponto em que apenas possamos conceber que há encontro e conexão entre heterogêneos.

A intensificação da heterogeneidade, que Guattari pensará sob o nome de heterogêneses, poderia ser caracterizada do seguinte modo: uma conexão entre heterogêneos que, no momento do encontro não só não perdem as suas heterogeneidades como, a partir delas, por conta delas, além de criarem algo inteiramente novo, recriam-se a si mesmas.

E tal empreendimento, nem racionalista, humanista, epistemológico, idealista, nem realista ou metafísico será chamado por Deleuze e Guattari (1995, p. 8), no prefácio que escreveram para a edição italiana de MilPlatôs, de "construtivista". O que é crucial para o construtivismo? Como escrevem Deleuze e Guattari (1997, p. 133), também em Mil Platôs, “é uma questão de consistência: o ‘manter-se junto’ de elementos heterogêneos". E se o construtivismo não é um relativismo, isso ocorre na medida em que não há princípio de equivalência, sem abrir mão de um poderoso critério de avaliação: "Não se trata mais de impor uma forma a uma matéria, mas de elaborar um material cada vez mais rico, cada vez mais consistente, apto a partir daí a captar forças cada vez mais intensas. O que torna o material cada vez mais rico é aquilo que faz com que heterogêneos mantenham-se juntos sem deixar de ser heterogêneos" (1997, p. 141).

Todo este livro, onde está o enunciado aqui tantas vezes repetidos, e seus principais conceitos, vibram a partir desse ritmo construtivista e servem para repensar certos dualismos sacralizados pela mesma tradição ocidental da filosofia e da política. Assim, poderíamos nos perguntar: o que surge da oposição entre o uno e o múltiplo se o uno que organiza o múltiplo for subtraído e a oposição desfeita? O múltiplo ganha sua consistência própria e se torna uma multiplicidade. O que surge da oposição entre singular e universal se o universal que subsume o singular como particular for subtraído e a oposição desfeita? O singular ganha sua consistência própria tornando-se singularidade (e processo de singularização). O que surge, enfim, da oposição entre ser e devir, uma vez que o ser, responsável por organizar, subsumir e julgar a transformação da existência, a mudança incessante, for subtraído e também a oposição desfeita? Não um conceito de devir como ser verdadeiro, optando pela instabilidade essencial lá onde estava a estabilidade, mas sim uma potência própria de criação do próprio real.

Estamos diante de uma experiência do pensamento que está interessada em pegar o real não sob sua forma já aí, seja o já aí das coisas que podem ser imediatamente percebidas pela percepção dominante ou uma já aí profundo, fundamento ou condição de possibilidade da experiência, apreendido apenas pela atitude Crítica. Trata-se de um real em vias de se cristalizar, de adquirir consistência, sempre precária, provisória e, por conta disso, exigindo refinados exercícios pragmáticos, técnicos e estéticos de recomposição. É somente aí, aliás, que o sentido forte de fazer, fabricar, forjar algo, em suma, do que 
pode ser chamado de práxis, pode aparecer em toda sua intensidade, uma vez que também as garantias e certezas foram subtraídas. Um mundo que se enriquece em possibilidade de vida, um pouco que seja, também se torna mais delicado e mesmo mais perigoso.

Antes do ser, existe a política, então, pois antes do ser, há o devir. A política é um caso de devir antes de ser do ser. Ou ainda: a política diz também respeito ao ser na medida em chega até ele através do devir. Essa anterioridade da política presente nesse enunciado não possui a simples pretensão de apenas afirmar que não existe um real em si e que todo discurso e conhecimento sobre o mesmo seja sempre político, isto é, humano, convencional ou consensual - quer se trate de um consenso racional e consciente ou de um consenso oriundo de um complexo sócio-histórico determinado, implícito, estrutural. O construtivismo de Deleuze e Guattari não é um relativismo que sempre supõe uma constante absoluta para permitir que em outra esfera do real possam ocorrer às variáveis. A questão passa muito mais por tentar pensar o que se torna a política quando ela é um caso de devir antes de ser do ser sem que isso implique uma inversão do dualismo entre ser e devir, - o que restabeleceria todos os outros dualismos. E devir, para nós, é precisamente um ato de criação que sustenta, através da conexão entre heterogêneos, uma práxis provisoriamente bem-sucedida. O cerne do devir, assim, na sua criação de real, está na passagem ou conexão que ele cria entre heterogêneos que permanecem como tais. O devir é uma experiência em que a conservação da heterogeneidade anda necessariamente junto com a transformação dos mesmos termos ou elementos heterogêneos que se conectam ${ }^{7}$.

Assim, no mínimo não seria absurdo especular que um ato de criação em política ocorre quando se criam os modos de conexão entre heterogêneos; quando o problema da tomada de consistência existencial aparece em toda sua intensidade, isto é, em sua dimensão problemática, sem garantias determinadas a priori. E, nessa sequência, quando o problema da avaliação da tomada de consistência que está em vias de surgir através da conexão entre heterogêneos remete continuamente aos graus ou coeficientes de liberdade que a consistência em jogo possui para recolocar o próprio problema da tomada de consistência.

Em outras palavras, a política antes do ser é o acontecimento de uma conexão entre heterogêneos que cria uma consistência inteiramente singular capaz de colocar o problema da recriação tanto dos elementos heterogêneos quanto da conexão que mantém a liga. Trata-se de uma aposta, de uma experimentação, que abre o campo de possíveis para outras experimentações. Ainda que, é preciso

\footnotetext{
${ }^{7}$ Ressaltamos que o devir, por isso, nunca é um devir em geral. Ele é sempre qualificado: devir-animal, devir-molecular, devirimperceptível... Depois, vale apontar que o devir implica uma realidade própria que possui uma diferença de natureza com a realidade dominante. Precisamente nesse sentido é que ele é indiscernível de um ato de criação. Por exemplo, um devir-animal de um músico só ocorre através de uma prática de criação qualificada, bem como dos meios que ela dispõe e são forçados a funcionar sob outras maquinações. O músico e o animal permanecem sendo exatamente o que são, irredutíveis um ao outro e, ao mesmo tempo, deixam de ser o que são a partir do modo de conexão cultivado na práxis da ecologia musical responsável pelo encontro. Nesse movimento, a própria música se relança, torna possível o que não era e resiste, pela criação, aos dispositivos de equivalência generalizada que promovem à expansão da homogênese capitalista. Assim, "todo devir é um devirminoritário". E a criação que cria o real onde o devir acontece nunca é feita a partir do nada, nem é histórica. Poderíamos dizer: trata-se sempre de uma recriação sui generis. Sobre estas e outras dimensões do conceito de devir, conferir o platô intitulado "1730 - Devir-intenso, devir-animal, devir-imperceptivel..." (DELEUZE; GUATTARI, 1997, pp. 11-113).
} 
sublinhar, essa recriação contínua da heterogeneidade não se efetue de um modo evolucionista ou progressista, ou seja, não requer a destruição de meios, vínculos e modos de pertencimentos que qualificam a textura mesma do heterogêneo e que ativa o material, virtual, de transformações infinitas.

A política aparece, assim, da ordem de um problema acerca da consistência dessa conexão. Dessa maneira, mesmo a incompossibilidade, o silêncio e a distância podem fornecer materiais de possíveis para manter juntos, dar liga, ao ato de criação política. Observamos apenas que a heterogeneidade conectada por vias ou componentes de passagem não é nunca uma heterogeneidade qualquer, das coisas, do mundo ou de estruturas profundas. Não há, assim, uma espécie de fenomenologia e nem ontologia política. A heterogeneidade, para Deleuze e Guattari, diz respeito aos modos heterogêneos de criação. As entidades heterogêneas só podem ser encontradas na medida em que compõe um processo de heterogêneses, uma práxis. As vias ou componentes de passagens próprias da política se instauram entre atos de criação de conexões. E o ato de criação da política é um ato de criação de conexões entre práticas de criação - entre práticas que ao se singularizarem inventam os meios e os valores que permitem com que os modos de existência a elas atreladas se tornem dignos de existir. Toda criação, nesse sentido, é já um ato de recriação. A política, antes do ser, é uma questão existencial, de uma existência que não está fadada a ser um mero efeito de superfície de um ser fundamental - nem origem, nem disfarce, nem acesso ou ponte para o ser, para a verdade e para o status quo capitalístico dominante.

\section{Concluindo momentaneamente}

Cada cartografia, dirá Guattari (2013, 507-508), “sempre guarda em seu coração um núcleo de incerteza. É, na verdade, seu capital mais precioso. É a partir dele que se pode constituir uma autêntica escuta do outro. A escuta da disparidade, da singularidade, da marginalidade, mesmo da loucura, não depende unicamente de um imperativo de tolerância e fraternidade”.

Esse vocabulário da incerteza está atrelado a um outro, componente essencial de toda temática da "política antes do ser". Trata-se do esforço constante de Guattari $(1992,162)$ para que não seja, no mínimo, totalmente improvável, o acontecimento de conexões que impliquem "a promoção permanente de outros agenciamentos enunciativos, outros recursos semióticos, uma alteridade pega em sua posição de emergência - não xenófoba, não racista, não falocrática - devires intensivos e processuais, um novo amor pelo desconhecido...".

O que é, o que obrigar a pensar, esse novo amor pelo desconhecido ${ }^{8}$ ? Como ele participa do ato de pensar às multivalências da produção de subjetividade em vias de singularização, no ato mesmo em que fazem passar modos de existência que não estão em conformidade com os valores dominantes? E o

\footnotetext{
${ }^{8}$ Explicito que as formulações que aqui são feitas referenciam-se tanto naquilo que Deleuze e Guattari (1991, p. 8), em Qu'estce que la philosophie?, chamaram de "os desconhecidos da questão" quanto no prolongamento desta última obra efetuado por Stengers (2003, p. 76), em Cosmopolitiques, quando pensava o que batizou de "a questão dos desconhecidos".
} 
fato desse amor ser qualificado de novo deve ser destacado, pois não se trata do amor fusional, devastador, em que o outro é invadido e conquistado. Esse amor pelo desconhecido está mais próximo daquilo que Deleuze e Guattari $(1996,59)$ caracterizavam como "um amor vivo, não subjetivo, no qual cada um se conect[a] com os espaços desconhecidos do outro sem entrar neles nem conquistá-los, no qual as linhas se compõe como linha partidas". É este o amor pelo desconhecido um componente determinante do problema das conexões entre heterogêneos, na medida em que ele chama atenção para um desconhecido que o acompanha. Poderíamos formulá-lo mais ou menos assim: não sabemos o que pode uma conexão.

Essa formulação não deve indicar, evidentemente, que Guattari ou quem quer que seja possa deter o saber que permite definir o que é a conexão, julgando que ninguém mais o sabe. Nem, por outro lado, afirmar que não existem conexões, heterogêneses, que ninguém, inclusive Guattari, as conheceria, e que seria preciso sempre começar do zero. Tudo se passa como na célebre formulação de Spinoza, "não sabemos o que pode um corpo...”, tal como foi interpretada por Deleuze $(2002,23)$, isto é, como uma explicitação produtiva de um atestado de nossa ignorância: um desconhecido que deve acompanhar os processos não de definição ou regência universal das conexões de uma vez por todas, mas sim de sustentação do problema das conexões em vias de se fazer entre meios de criação, a cada vez.

“Nós não sabemos o que pode um corpo". Deleuze vai dizer: tagarelamos (aqueles herdeiros dos valores socrático-platônicos e teológicos de matriz judaico-cristã) demais sobre o espírito, sobre a consciência, sobre a verdade e desconhecemos às potências do corpo. Desde que nascemos nutrimos encontros com as afecções tristes, desconhecemos o que poderíamos nos tornar capazes de pensar, de sentir e de agir sob outras composições, em outras conexões, em outros meios... A fórmula desse grito é uma reação, sem dúvida, a um certo estado de coisas. Mas é também algo que vai além disso: a tentativa de imaginar, de criar e de especular sobre as potências do corpo que poderiam aparecer de modo autopoiético se nós neutralizássemos, se nós desviássemos o olhar, daquilo que bloqueia um campo de possíveis inteiramente novos da experimentação (começando pela própria cortina de ferro ontológica alojada entre o corpo e o espírito).

Trata-se de uma questão de valor: como captar e se conectar com o que importa? Como criar importância lá onde tudo parece se equivaler? Tal é a tarefa estética, ética e política da criação daquilo que também Guattari chamou de "território existencial”: espaço-tempo existencial capaz de repetir uma certa consistência, através dos materiais mais finitos, qualificados, cotidianos, criando o possível para uma abertura contínua da vida, que se confunde com sua intensificação e a invenção de sua dignidade.

Por outro lado, é essa, sob o regime capitalístico, a coisa mais sufocada do mundo. O que é o valor capitalista senão aquele do equivaler generalizado onde tudo parece ser dragado para um valor cuja peculiaridade é esvaziar tudo de importância, de liga, de relançamento existencial? A perspectiva de Guattari, assim, de pensar a inseparabilidade das práxis de conexão com o valor, o que importa em uma prática, passa, também, por colocar a seguinte questão: como não continuar o procedimento capitalístico por excelência que promove uma radical e sistemática desvalorização daquilo que importa para certas 
práticas, certos meios, certos modos de existência? Em suma: como resistir a desvalorização capitalística que se manifesta no seu mais obstinado sistema de equivalência generalizada?

Notemos também que a consideração desse desconhecido, desse não saber do que uma conexão é capaz, por exemplo, não serve para que, em algum momento, de uma vez por todas, se saiba, enfim, o que é possível. Levantar a hipótese de um desconhecido enquanto tal implica não desejar apaziguá-lo com o momento em que finalmente ele seria eliminado. Trata-se de desenvolver uma avaliação, em relação aos efeitos pragmáticos que este desconhecido, ativo, enquanto tal, pode desencadear em uma certa prática, em um certo meio, em relação a um problema e a um agenciamento considerado.

Também não é o caso, nesta direção, de um simples reconhecimento de que não se sabe algo, ou de que nada se sabe, tal como na presunçosa formulação socrática que pretendia fazer do desconhecido mais um artifício de julgamento dos outros, daqueles enquadrados no reino da opinião e que apenas pensavam que sabiam mas não sabiam de nada, sobretudo do fato de suas ignorâncias. Nem se trata, tal como aparece na versão kantiana, de um desconhecido inacessível, que impossibilita que conheçamos algo em sua realidade mesma, mas apenas a partir de categorias e formas a priori universalmente partilhadas pela subjetividade humana que conforma sempre ao seu modo e segundo seus limites os fenômenos que faz aparecer.

E ainda: Guattari não faz eco ao desconhecido, digamos assim, pós-moderno, pobremente relativista, individualista, crispação do kantismo, que utiliza uma suposta crítica à objetividade, uma suposta consideração dos componentes subjetivos no conhecimento, para postular que permanecerá desconhecido tudo aquilo que não é a experiência pessoal, individual, acarretando que só se deve falar eternamente de si mesmo e das experiências supostamente reservadas e privadas - tornando, ao seu modo, impensável quaisquer possíveis oriundos de conexões entre heterogêneos, estas sendo apenas expansões de um Eu eternamente reencontrado.

Talvez ninguém tenha prolongado de modo mais intenso essa problemática, implícita e explicitamente, como a filósofa Isabelle Stengers o fez - estando aí compreendida a questão do sentido e do valor em herdar e prolongar a própria atividade da filosofia. Como cultivar esse novo amor pelo desconhecido é inseparável do ato de hesitar diante daquilo que a filósofa chamou de "golpe da caverna" (2003, 87). Aqueles vinculados a uma variada e complexa modulação de modos de produção da subjetividade situados no ocidente, sobretudo em seu sentido moderno, como a ciência, a filosofia e, principalmente, a política - incluído o modo militante, progressista, de esquerda - estão sempre na iminência de refazê-lo. Este golpe da caverna que pode ser caracterizado como a atitude de sempre definir os outros como perdidos, alienados e ignorantes; universalizando à exigência de missões civilizadoras para conscientizar, educar, guiar, curar, governar... E, portanto, necessitando sempre de uma vanguarda política com o programa justo e correto, de pretendidos filósofos e intelectuais de todo tipo, iluminados, que devem libertar os prisioneiros, presos no mundo das opiniões, das crenças e das ilusões. 
O desconhecido envolve uma hesitação em relação à pretensão de definir, sempre, às supostas amarras dos outros - às insuficiências, indisponibilidades e más vontades para coexistir. Sem excluir desse movimento - que é o movimento mesmo de tentar não refazer o golpe da caverna - o fato de não se arrogar privilegiado de, enfim, desconfiar de todas as verdades, principalmente àquelas que supostamente teriam nos constituídos e das quais, por decreto e iluminação, poderíamos nos ver livre de uma hora para outra. Verdades que seriam, enfim, acompanhadas da certeza que constitui o drama do "adeus (efetuado por alguns em nome de todos) à segurança perdida". Atualização, escreve Stengers (2003, 87), do "grande tema platônico da saída da caverna que se encontra, assim, reinventado sob o novo modo da ascese heroica em relação às antigas promessas do progresso". Em Chaosmose, escrevia Guattari (1992, pp. 179180):

\begin{abstract}
Assim sendo, os intelectuais e artistas não têm lição para dar a ninguém. Para retomar uma imagem que eu desenvolvi há muito tempo, eles confeccionam caixas de ferramentas compostas de conceitos, de perceptos e afetos, de que diversos públicos farão uso segundo sua conveniência. Quanto à moral, é preciso admitir que não existe pedagogia dos valores [...] Le Pen tornou-se um objeto de atenção da libido coletiva quer para o elegê-lo ou para o rejeitá-lo - por conta de sua habilidade em ocupar a cena midiática mas também, principalmente, em razão do desmoronamento dos Territórios existenciais da subjetividade disso que chamamos esquerda, da perda progressiva dos seus valores heterogenéticos relativos ao internacionalismo, ao antirracismo, à solidariedade, às práticas sociais inovadoras... Independentemente de quem sejam, os intelectuais não deveriam mais ser chamados a se erigir como mestres do pensamento ou aqueles que vão dar lições de moral, mas sim a trabalhar, ainda que seja na extrema solidão, para colocar em circulação instrumentos de transversalidade.
\end{abstract}

A questão é concreta. Resistir ao golpe da caverna - que reatualiza constantemente à certeza de que nossos valores, nossas palavras, nossos modos de veiculá-las e apresentá-las, nossa boa vontade e nossa constante certeza de que devemos ocupar a posição de poder que determinaria às boas condições que possibilitariam os encontros entre heterogêneos - é trabalhar pela recriação de um "outro mundo de possíveis" um pouco menos asfixiantes.

Uma política antes do ser? Por quais motivos ainda chamar de política isto que vem antes do ser é, e permanecerá, uma questão em aberto. Mas, sem dúvida, o enunciado "antes do ser, há a política”, nos convida para uma política encarada em sua dimensão incontornavelmente existencial, problemática e problematizante, sem as garantias dos universais?.

\footnotetext{
9 Talvez, em parte, era isso que Guattari desejava pensar através do que chamava micropolítica: “a dimensão política deriva para uma dimensão micropolítica e analítica, a qual é fundamentalmente inapreensível em termos de militância. Isso não quer dizer que a dimensão micropolítica implique uma implosão contestadora, que proíba toda e qualquer possibilidade de organização da palavra, da ação etc. Quer dizer simplesmente que tal dimensão vai reinjetar de maneira contínua todos os elementos a-significantes, todos os elementos de singularidade; ela vai tornar complexas as questões no momento em que, finalmente, pareciam ser bastante simples; momento em que se pensava ter conseguido chegar a um acordo. É exatamente esse o momento em que se vê que não é nada disso, pois a própria existência reemerge em sua singularidade. Essa é a dimensão - eu diria a linha de fuga - da micropolítica fora do campo do militantismo” (Guattari, 2005, 352).
} 


\section{REFERENCIAS}

ABREU, Ovídio. O Combate ao Julgamento no Empirismo Transcendental de Deleuze. Rio de Janeiro: UFRJ (Tese de Doutorado), 2003.

CHÂTELET, François. História da filosofia: idéias, doutrinas. A filosofia pagã (volume 1). São Paulo: Zahar, 1973.

COSSERY, Albert. As cores da infâmia. São Paulo: Conrad, 2004.

DELEUZE, Gilles. Conversações. São Paulo: Ed. 34, 1992.

DELEUZE, Gilles. Espinosa: filosofia prática. Escuta: São Paulo, 2002.

DELEUZE, Gilles. Diálogos; PARNET, Claire. Lisboa: Relógio D’Água, 2004.

DELEUZE, Gilles; GUATTARI, Félix. Qu'est-ce que la philosophie? Paris: Minuit, 1991.

DELEUZE, Gilles; GUATTARI, Félix. Mil Platôs: capitalismo e esquizofrenia (vol. 1). São Paulo: Ed. 34, 1995.

DELEUZE, Gilles; GUATTARI, Félix. Mil Platôs: capitalismo e esquižfrenia (vol. 3). São Paulo: Ed. 34, 1996.

DELEUZE, Gilles; GUATTARI, Félix. Mil Platôs: capitalismo e esquizofrenia (vol. 4). São Paulo: Ed. 34, 1997.

DELEUZE, Gilles; GUATTARI, Félix. O anti-Édipo: capitalismo e esquižfrenia 1. São Paulo: Ed. 34, 2010.

DELEUZE, Gilles; GUATTARI, Félix. Kafka: por uma literatura menor. Belo horizonte: Autêntica, 2014.

DELEUZE, Gilles; GUATTARI, Félix. Segredo de fabricação - Deleuze e Guattari: nós dois. Revista Trágica: estudos de filosofia da imanência, Vol. 8, nº 2, pp.164-168, $2^{\circ}$ quadrimestre de 2015.

DOSSE, François. Gilles Deleuz̧e e Félix Guattari: biografia cruz̧ada. Porto Alegre: Artmed, 2010.

GUATTARI, Félix. O inconsciente maquinico: ensaios de esquizo-análise. Campinas: Papirus, 1988.

GUATTARI, Félix. Cartographies Schizoanalytiques. Paris: Galilée, 1989.

GUATTARI, Félix. As três ecologias. São Paulo: Papirus, 1990.

GUATTARI, Félix. Chaosmose. Paris: Galilée, 1992.

GUATTARI, Félix. La philosophie est essentielle à l'existence humaine. Paris: L'aube, 2002.

GUATTARI, Félix. Psicanálise e Transversalidade: ensaios de análise institucional. São Paulo: Idéias e Letras, 2004.

GUATTARI, Félix. La révolution moléculaire. Paris: Les prairies ordinaires, 2012.

GUATTARI, Félix. Qu'est-ce que l'écosophie? Paris: Lignes, 2013. 
GUATTARI, Félix; ROLNIK, Suely. Micropolítica: cartografias do desejo. Petrópolis: Vozes, 2005.

LIMA, Vladimir Moreira. A partir de Guattari 1: uma política da existência. Rio de Janeiro: Ponteio, 2019.

NEGRI, Antonio. 1994. Entretien avec Toni Negri sur Félix Guattari. Disponível em:

https://www.academia.edu/33313605/Entretien_avec_Toni_Negri_sur_F\%C3\%A9lix_Guattari_28_ja nvier_1994. Acessado em: 29 jul. 2019.

PIGNARRE, Phillipe; STENGERS, Isabelle. 2005. La sorcellerie capitaliste. Pratiques de désenvoûtement. Paris: La Découverte.

STENGERS, Isabelle. Cosmopolitiques I. Paris, La Découverte: 2003.

STENGERS, Isabelle. Activer les possibles. Noville-sur-Mehaigne: Esperluète. 2018.

Recebido em: 26 de abril de 2021. Aprovado em: 20 de junho de 2021. 